\title{
Research Paper \\ Evaluation of the Method of Binding Tamoxifen to DNA Experimentally and Computationally
}

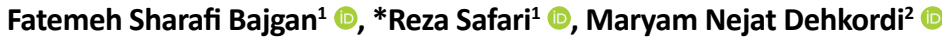

1. Department of Chemistry, Faculty of Science, University of Qom, Qom, Iran.

2. Department of Basic Science, Shahrekord Branch, Islamic Azad University, Shahrekord, Iran.

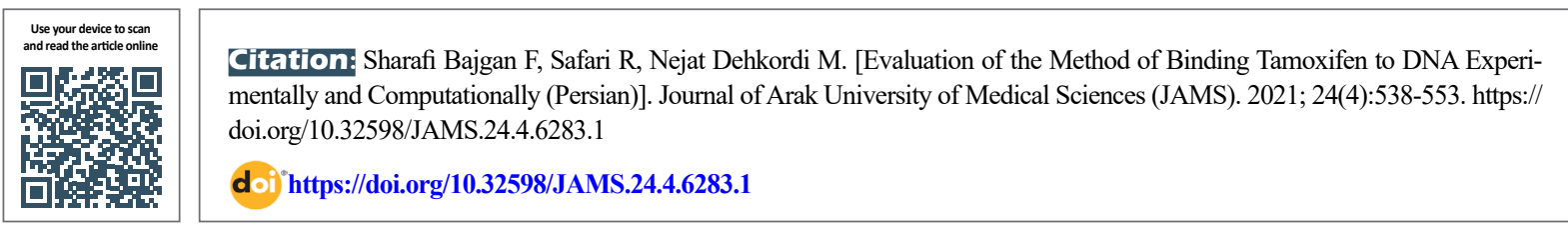

Article Info:

Received: 25 Aug 2020

Accepted: 23 May 2021

Available Online: 01 Oct 2021

Keywords:

Tamoxifen, DNA,

Binding, Spectros-

copy, Computational

Chemistry / Biology

\section{A B STRACT}

Background and Aim Tamoxifen is a group of drugs of selective estrogen receptor modulators, and is one of the drugs effective in the prevention and treatment of some cancers (such as breast cancer). In this study, the interaction of tamoxifen with DNA is investigated experimentally. Also, the electronic structure (at atomic scale) of the molecular system of tamoxifen was theoretically investigated, using atom in molecule (AIM) theory.

Methods \& Materials First, in the experimental section of this study, the interaction of Tamoxifen with DNA were investigated by UV-ViS technique and hydrodynamic method (Viscometry). In addition, the analysis of the experimental results shows the obvious effect of concentration on the mechanism of how the tamoxifen molecule binds to DNA. Then, in the theoretical part of this research, using computational biophysical chemistry methods, some properties of tamoxifen molecular system, such as electronic Density of States (DOS), boundary orbital's energy (HOMO/LUMO), Electrostatic Potential Energy (EPS) and electronic contour maps of the electron density and its Laplacian, will be calculated.

Ethical Considerations This article is a meta-analysis with animal sample.

Results Result of the UV-ViS spectroscopy technique and viscometry indicated hyperchromism and hypochromism effect. In addition, the result were depend on the concentration of the drug and affected the kind of binding of Tamoxifen to DNA. the analysis of computational studies on the drug tamoxifen suggests that the mechanism of the local charge/energy distribution in the molecular system of tamoxifen plays an important role in how this drug binds to DNA.

Conclusion Based on the experimental results of UV-ViS technique and viscometry, as well as the electronic/vibrational properties of the tamoxifen molecular system, it was defined that the Tamoxifen interacts significantly with all the binding sites of DNA.

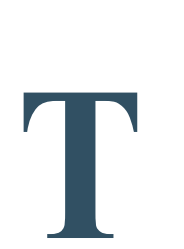

Extended Abstract

\section{Introduction}

amoxifen is a group of drugs of selective estrogen receptor modulators. Moreover, it is effective in preventing and treating some cancers (e.g., breast cancer). This study experimentally explored the interaction of tamoxifen with DNA. Moreover, the electronic structure (at the atomic scale) of the molecular system of tamoxifen was theoretically investigated, using Atom in Molecule (AIM) and Natural Bond Orbital (NBO) theories.

\section{* Corresponding Author:}

Reza Safari, PhD.

Address: Department of Chemistry, Faculty of Science, University of Qom, Qom, Iran.

Tel: +98 (253) 2103096

E-mail: r.safari@qom.ac.ir; safari_physicalchemistry@yahoo.com 


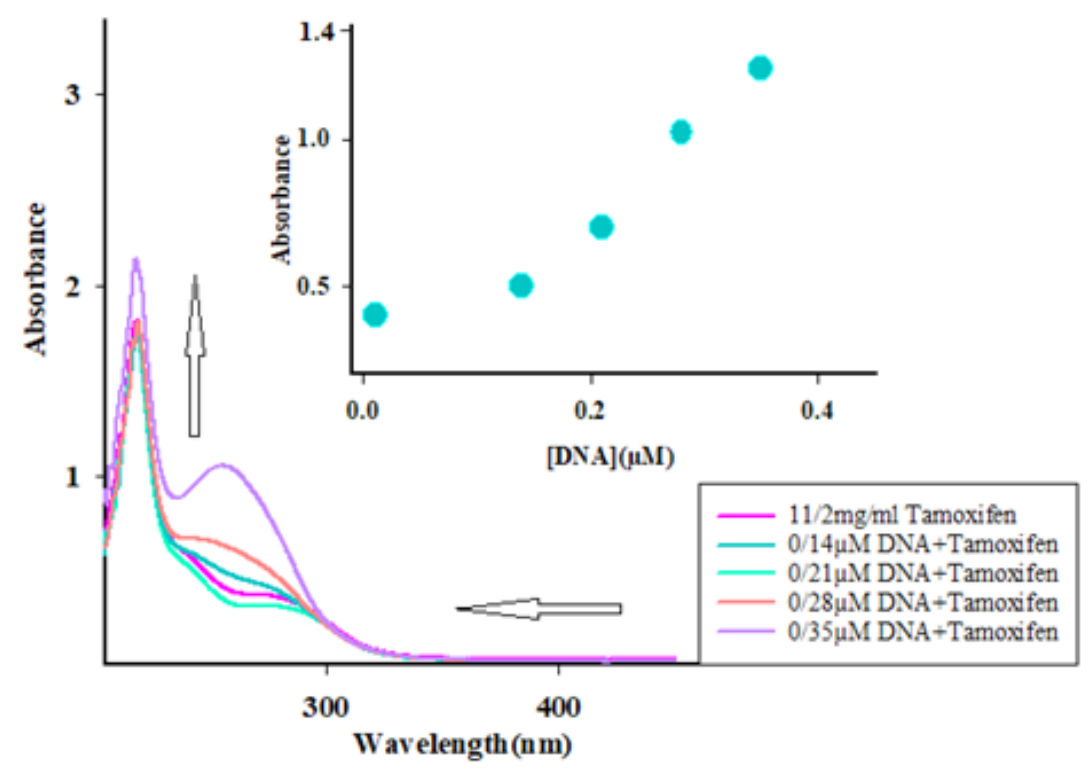

Figure 1. The absorption spectra of Tamoxifen titrated with the DNA solution

\section{Materials \& Methods}

In the experimental section, using the ct-DNA and Tris buffer and other solution and materials, the interaction of Tamoxifen with DNA was investigated by UV-ViS technique and hydrodynamic method (Viscometry). Then, in the theoretical part of this research, using computational biophysical chemistry methods, some properties of tamoxifen molecular system, such as electronic Density of States (DOS), Boundary Orbital's Energy (HOMO/ LUMO), Electrostatic Potential Energy (EPS), and the electronic contour maps of the electron density and its Laplacian were calculated.

\section{Results}

According to the obtained results, Figures 1 and 2, of the UV-ViS spectroscopy technique andviscometry indicated hyperchromism and hypochromism effect. Furthermore, the experimental results were depended on the concentration of the drug and affected the type of binding of Tamoxifen to DNA. Besides, the entangling of the whole binding sites of DNA was due to the hydrophobic and electrostatic interactions $[11,12]$.

Additionally, analyzing computational studies on the drug tamoxifen suggested that the mechanism of the lo-

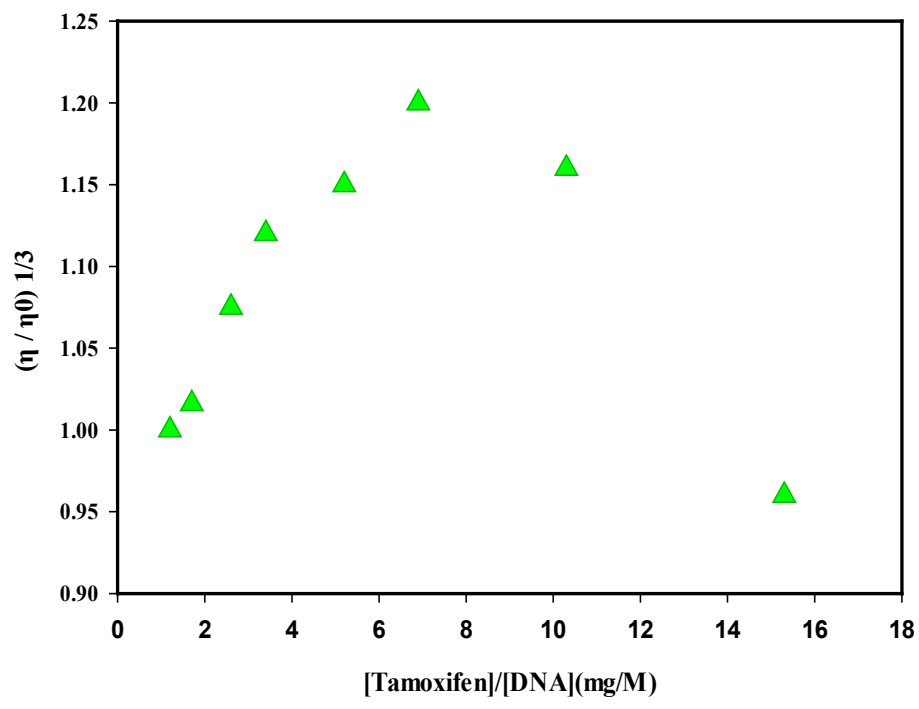

Figure 2. The relative viscosity of DNA $(52 \mu \mathrm{M})$ versus (Tamoxifen/DNA) concentration 


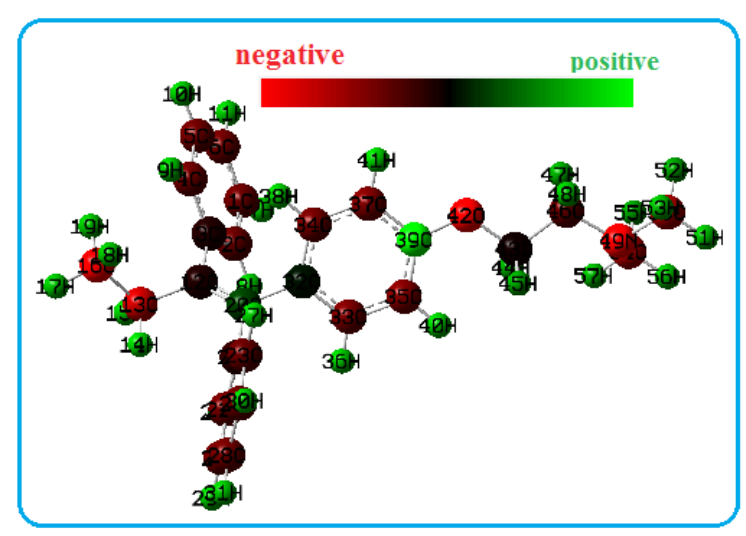

(a)

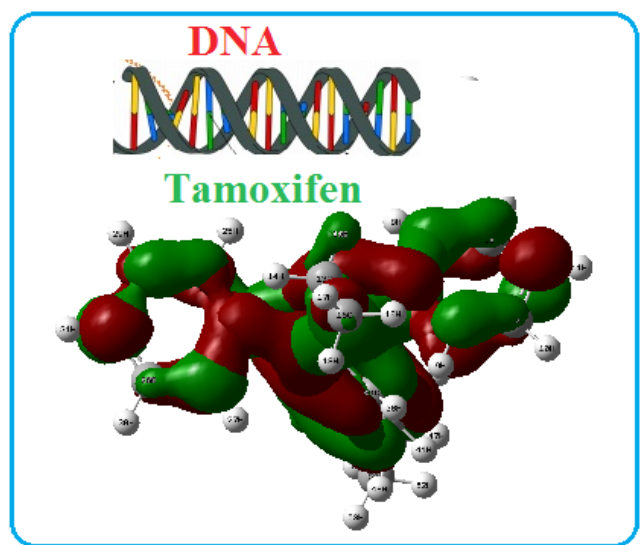

(b)

Arak University of Medical Sciences

Figure 3. A: Local atomic charge distribution in tamoxifen molecular system; and B: The expanded spatial orbitals of tamoxifen to predict how it binds/interacts to DNA.

cal charge/energy distribution in the molecular system of tamoxifen plays an essential role in how this drug binds to DNA, Figure 3.

\section{Discussion and Conclusion}

Based on the experimental results of the UV-ViS technique and viscometry, as well as the electronic/vibrational properties of the tamoxifen molecular system, it was defined that the Tamoxifencan place betweenthe base pairs, major and minor grooves; it also interacts with a back bone of DNA by electrostatic interactions. Therefore, all the DNA binding sites are entangled with Tamoxifen by the hydrophobic and electrostatic interactions. The internal diagram presents the absorbance of the tamoxifen in the presence of a different concentration of DNA at a wavelength of $250 \mathrm{~nm}$.

\section{Ethical Considerations}

\section{Compliance with ethical guidelines}

This article is a meta-analysis with animal sample.

Funding

The paper was extracted from the MSc. thesis of the first author at the Department of Chemistry, School of Science, University of Qom, Qom.

\section{Authors' contributions}

Subject design: Reza Safari, Maryam Nejat Dehkordi; Experiments and calculations: Fatemeh Sharafi Bajgan; Analysis of results: Reza Safari, Maryam Nejat Dehkordi, Fatemeh Sharafi Bajgan; Text writing and review: All authors.

\section{Conflicts of interest}

The authors declared no conflict of interest.

\section{Acknowledgements}

We would like to express our gratitude to the research assistants and managers of the esteemed departments of Chemistry in Qom and Islamic Azad University (Shahrekord Branch) for providing the necessary research facilities and equipment. 


\title{
ارزيابى شيوه ييوندى داروى تاموكسيفن با DNA به صورت تجربى و محاسباتى
}

\author{
فاطمه شرفى بجكان' هـ، "زضا صفرى' هـ مريم نجات دهكردى'
}

ا. كزوه شيمى، دانشكده علوم يايه، دانشكاه قمه قمه، ايران.

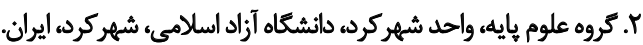

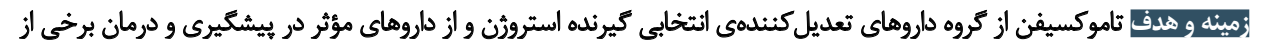

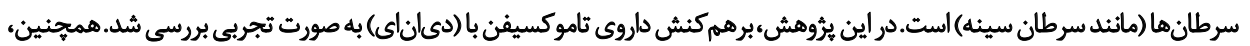

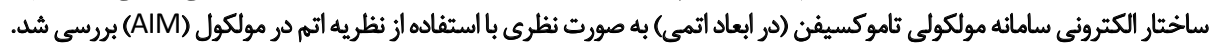

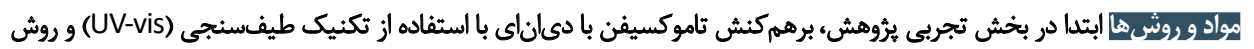

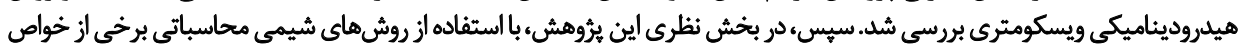

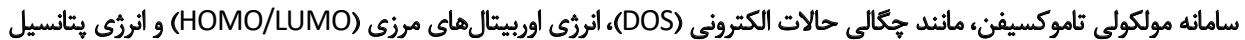

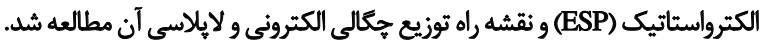

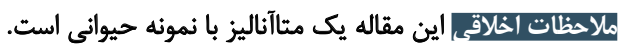

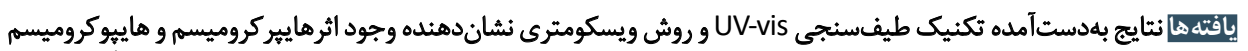

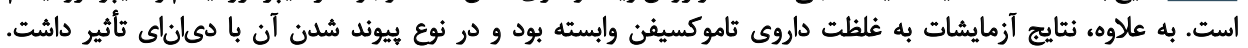

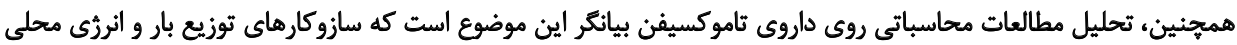

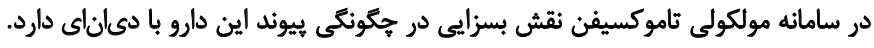

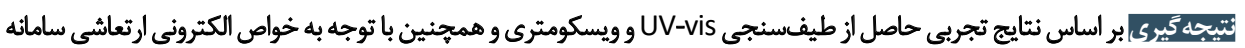

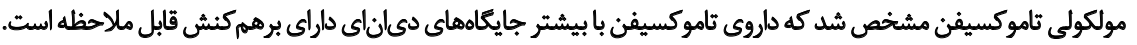

يكى از شايعترين بيمارىهايى كه امروزه طيف وسيعى از افراد

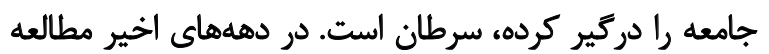

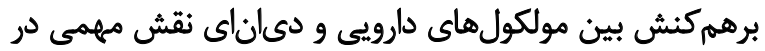

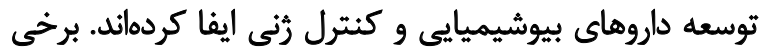

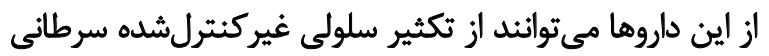

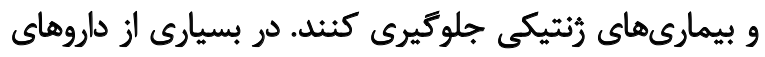

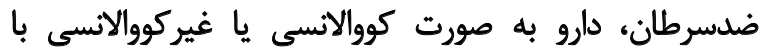

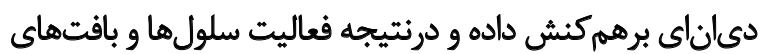
سرطانى را مختل مي كنيند [ب-1)] مطالعه جكونتى يهيوند دارو با دىاناى داراى اهميت زيادى 


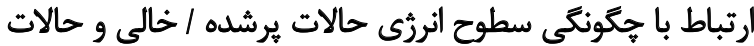

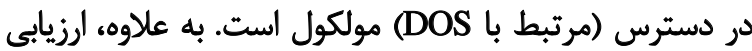

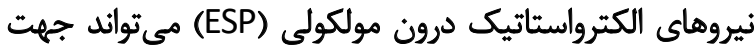

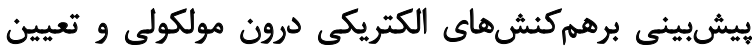

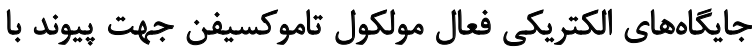

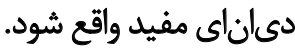

مواد و روشها بخش تجريى

محلولهاى موردنياز

در اين بخش از ئروهش، جهت مطالعه برهمكنش داروى دي

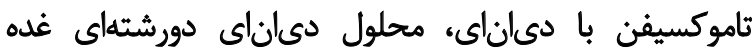

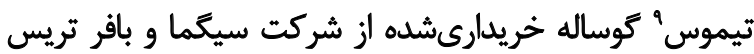

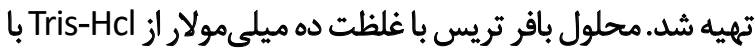

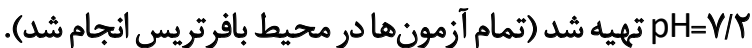

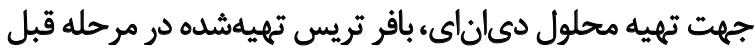

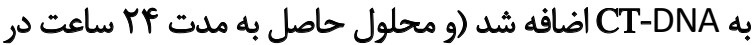
دماى يخحال جهت همغن بودن همزده شدل). تعيين غلظت دقيق محلول دىاناى با اندازهيرى جذب

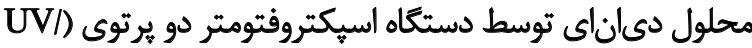

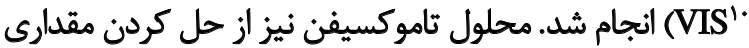

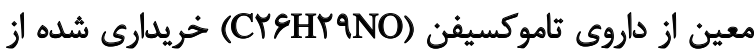
شركت ايران هورمون در محلول بافر تريس حاصل شد.

\section{روشهاى آزمايشكاهى}

با استفاده از تكنيك طيفسنجى UV-vis مى توان به مطالعه

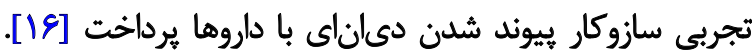

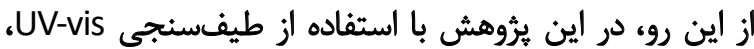

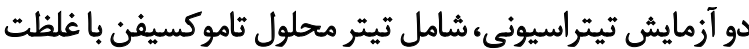

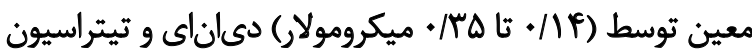

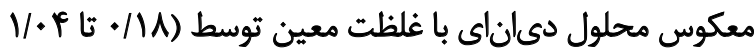
ميلى حاصل از آنها نيز با استفاده از نرمافزار " SP-14 رسم شدئ

به بلاوه، آزمايشات ويسكوزيته توسط ويسكومتر Petrotest

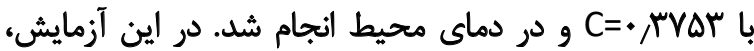

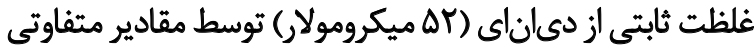

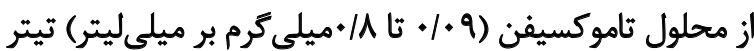

9. Calf Thymus

10. UV-Vis Spectroscopy

11. Sigma Plot14.0
سرطان سينه (در سينه مقابل) از سوى سازمان دارو و غذاي

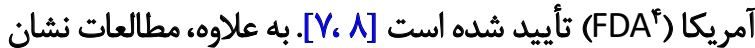

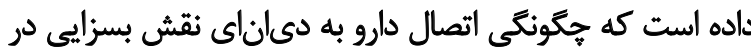

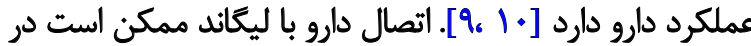

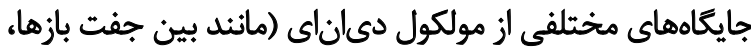

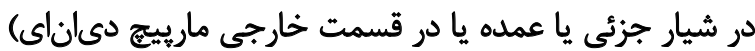

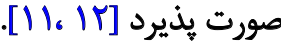

بر اساس كزارش آدام و همكاران بر اثر افزودن داروى

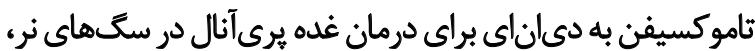

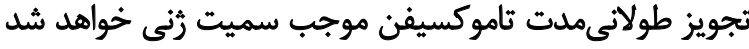

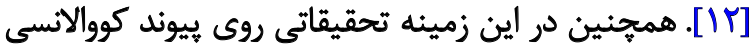

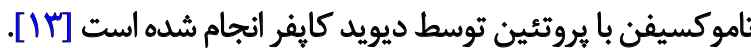

تحقيقاتى در مورد يهيوند تاموكسيفن با دىاناي موش توسط

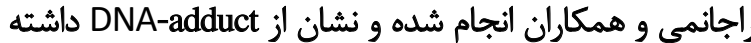

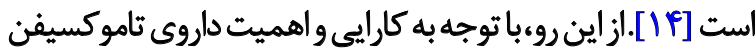

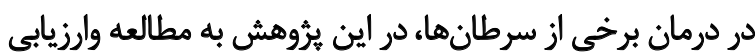

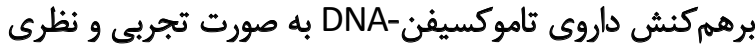

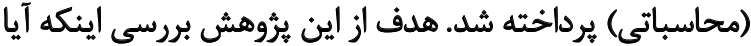

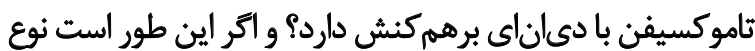

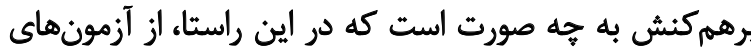
تجربى (مانند روش هاى طيفسنجي ونى و ويسكومترى) استفاده شد.

به علاوه، در بخش نظرى اين يُروهش به مطالعه محاسباتى

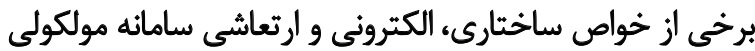

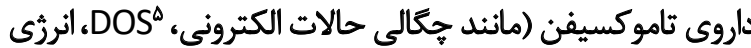

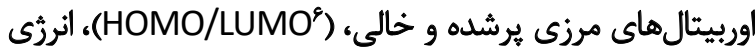

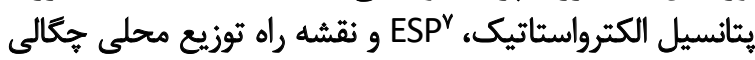

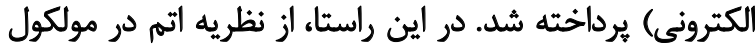

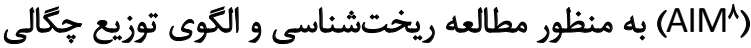

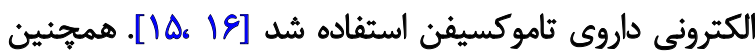
نقش مطالعه تئورى ساختار الكترونى ارتعاشى اين دائ دارو در كنار

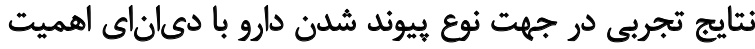

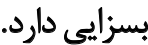

انتطار ميرود، بر اساس مطالعه و سنجش شكافت ميان أثرئى

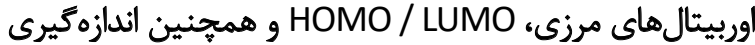

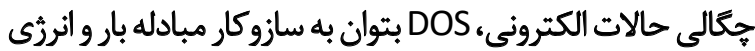

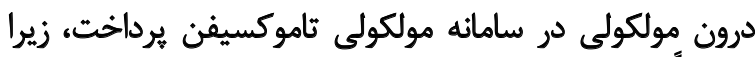

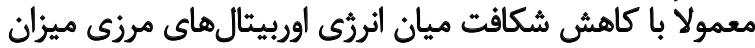

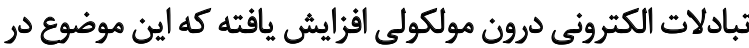

4. Food and Drug Administration

5. Density of States

6. Highest Occupied/Lowest Unoccupied Molecular Orbitals

7. Electrostatic Potential

8. Atoms in Molecule Theory 
مطالعه محاسباتي ساختار الكثرونى داروى تاموكسيفن

در اين بخش از يُروهش، ابتدا ساختار الكترونى ارتعاشى سامانه

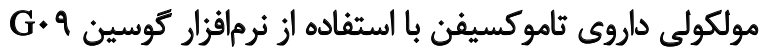

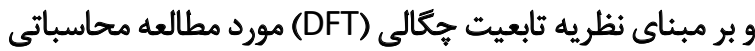

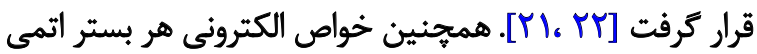

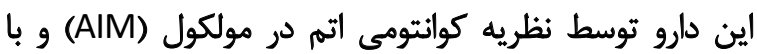

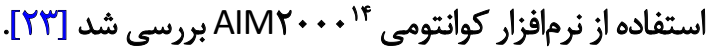

يافتهها

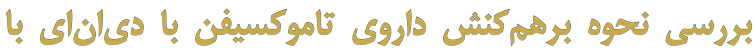

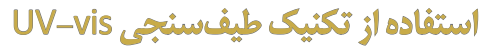

$$
\text { ثيثراسيون محلول ثاموكسيفن با دىاثاى }
$$

غلظت ثابتى از محلول تاموكسيفن توسط محلولى از دئى إناى

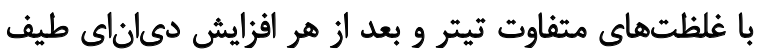
Uحلول جديد تاموكسيفن-DNA-vis

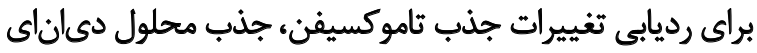

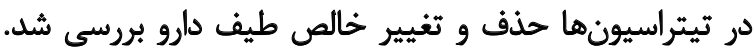

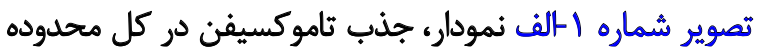

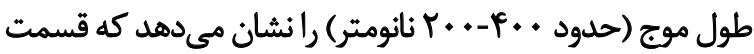

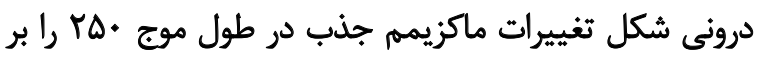
حسب غلظت دىاناي اضافهشده را نشان مي دهند.

\section{ثيتر اسيون معكوس دىانثاى}

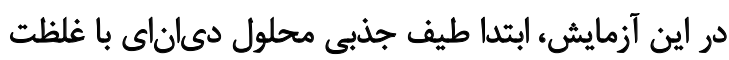

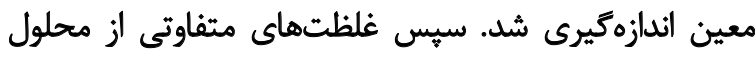

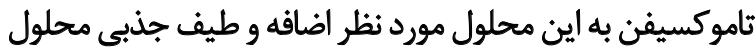

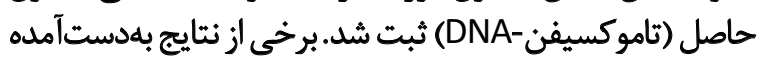

$$
\text { در تصوير شماره الالف نشان داده شده است. }
$$

به علاوه، براى رديابى تغييرات جذب دئ داناي، جذب محلول

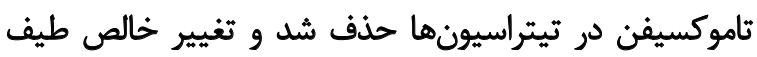

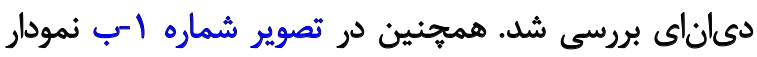

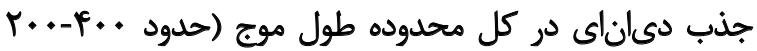

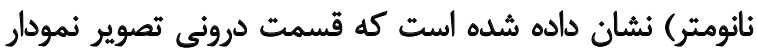

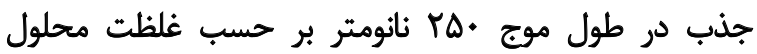
تاموكسيفن تيترشده است.

بروسي نُحوه برهم كثش محلول تاموكسيفن با دىانان ثوسط روش

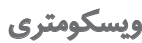
اندازهكيرى طيفسنجى UV-vis شواهد لازم، اما كافى را براى

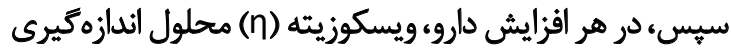

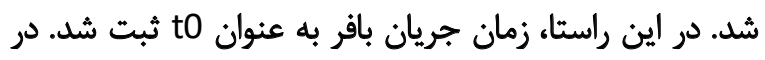

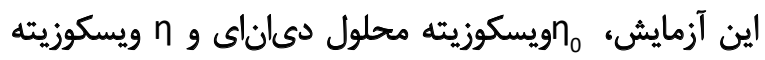

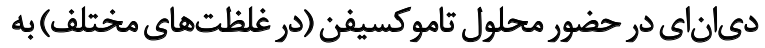

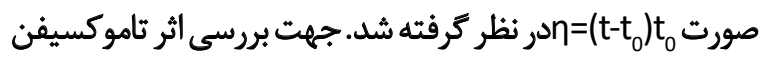

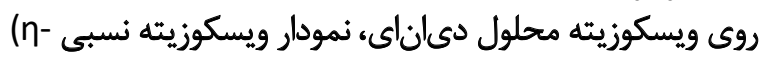

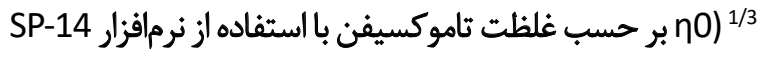

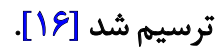

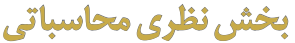

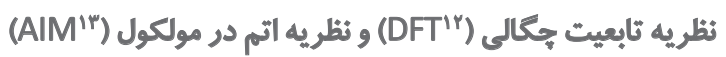

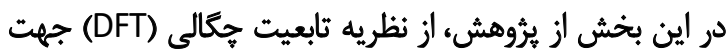

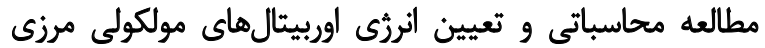

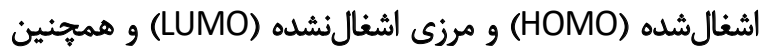

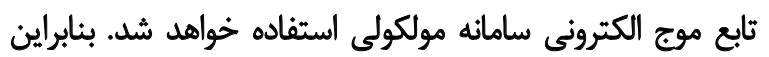

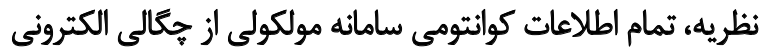

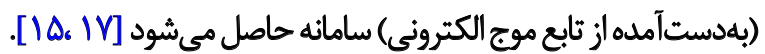
به علاوه،در اين يثروهش بر اساس نظريه اتم در مولكول (AIM)،

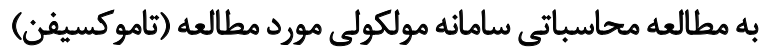

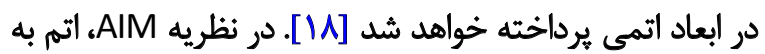

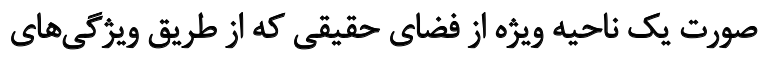

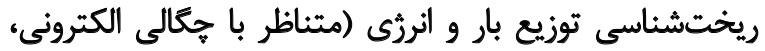

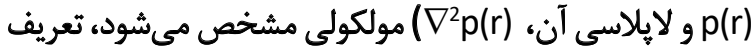

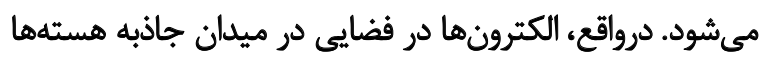

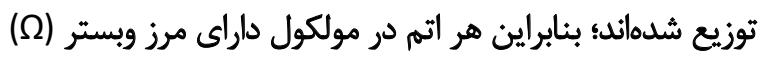

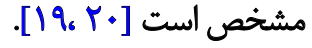

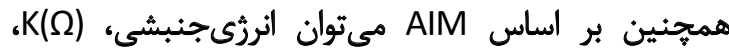

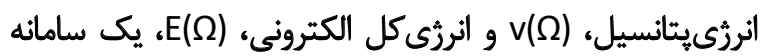
مولكولى رادر ابعاد اتمى، توسط روابط زير برئ دئ دست آوردي:

1) $\frac{-h^{2}}{2 m} N \int d r \int\left[\psi \nabla^{2} \psi^{*}+\psi^{*} \nabla^{2} \psi\right] d \tau^{\prime}$

2) $V(\Omega)=V_{\text {rep }}(\Omega)+V_{\text {ne }}(\Omega)$

3) $E(\Omega)=K_{\text {elec }}(\Omega)+V_{\text {elec }}(\Omega)$

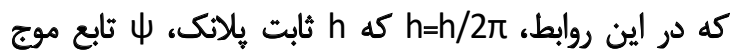

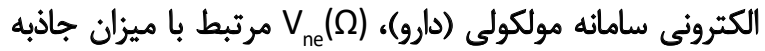

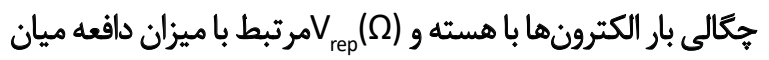

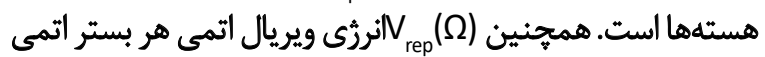

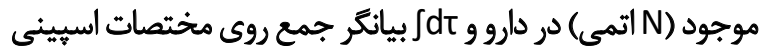
الكترونى الكترونهاى بسترهاى اتمى مورد نظر است. 

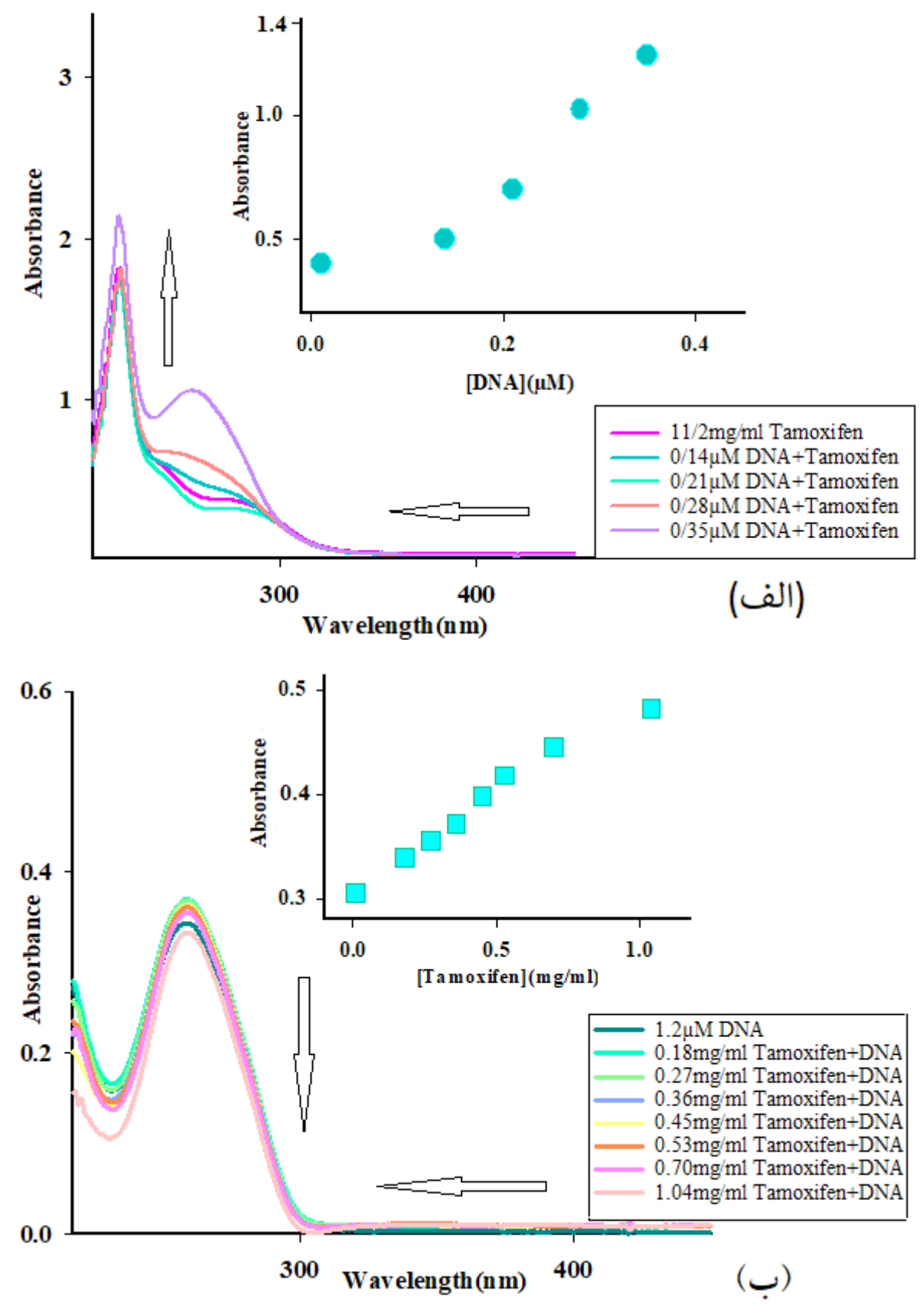

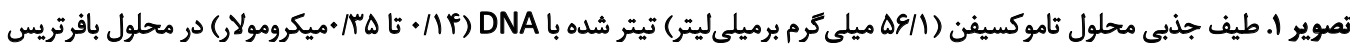

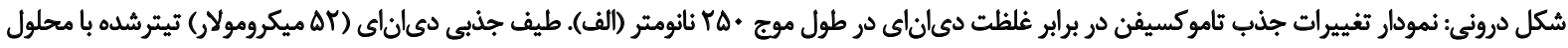

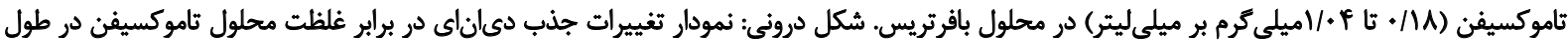

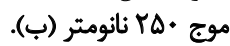

مىشود، زيرا در اثر اتصال ليكاند يا كميلكس به ديى انواى جفت بازها

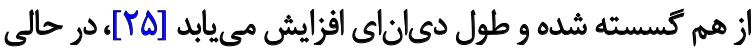

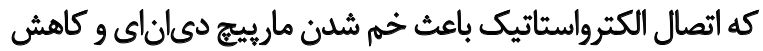

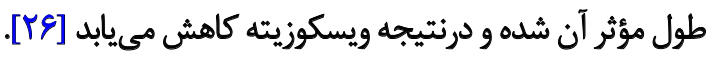
از اين رو، جهت تعيين نوع برهم كنش تاموكسيفن بادى ونهاني،

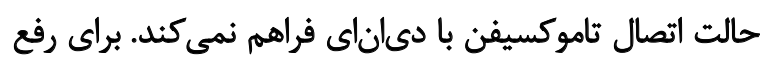

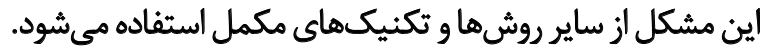

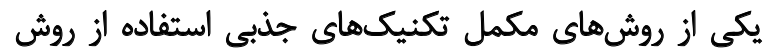

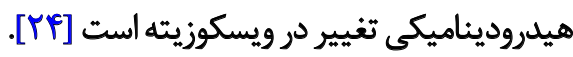

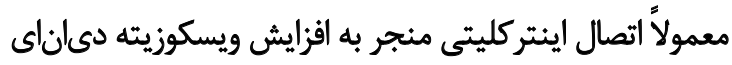




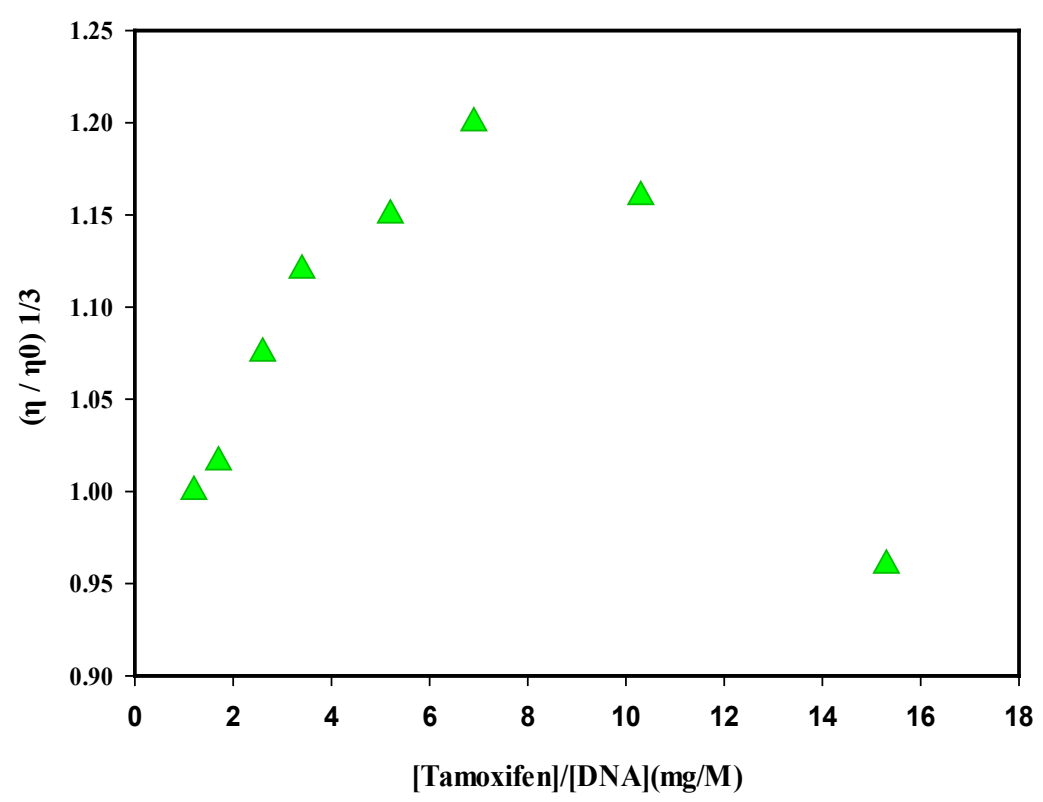

[Tamoxifen/DNA] تصوير r. تغييرات ويسكوزيته نسبى دىاناى (rه ميكرومولار) بر حسب غلظت

1، كزارش و در تصوير شماره f نشان داده شده است. بر اساس

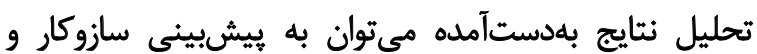

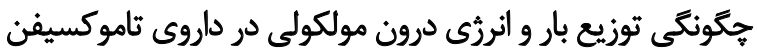

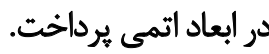

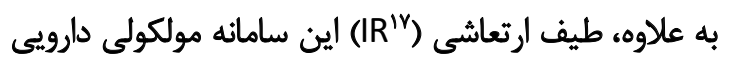

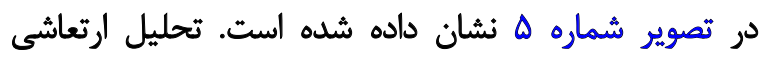

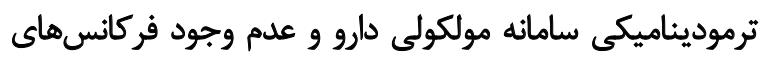

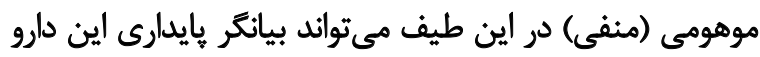

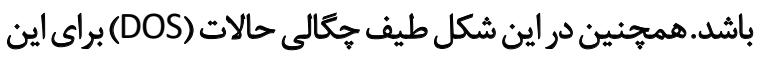

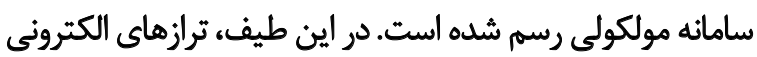

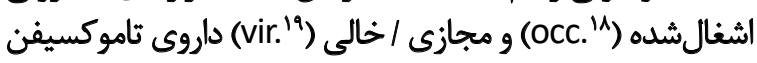

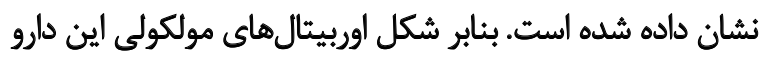

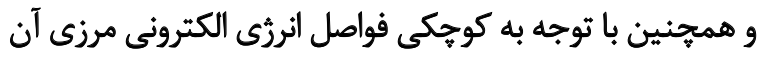

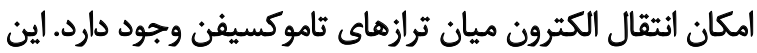

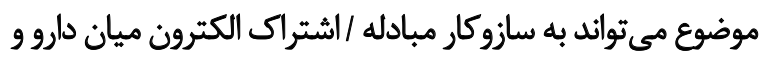

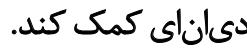

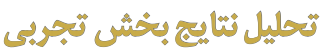

نتايج بخش تجربى طيفسنجى و ويسكومترى اين بروهش

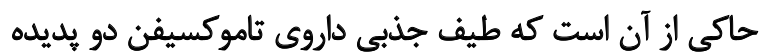

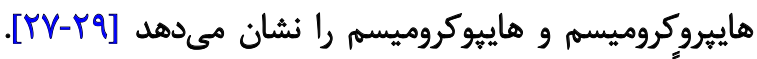

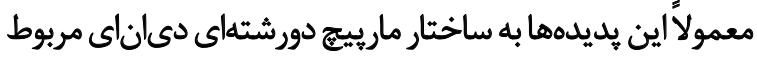

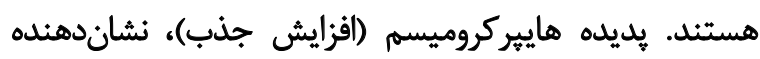

17. Infrared Spectroscopy

18. Occupied Molecular Orbitals

19. Virtual Molecular Orbitals

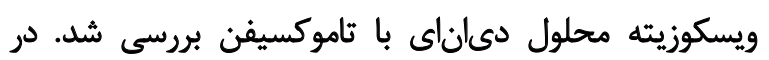

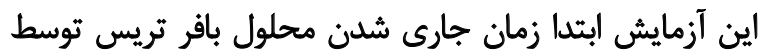

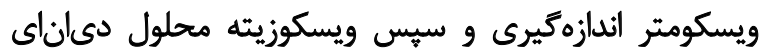

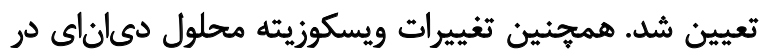

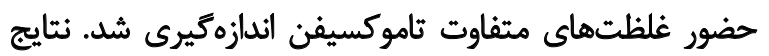

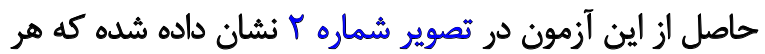
آزمون سه بار تكرار شده است.

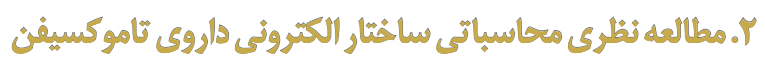

در اين بخش از يرؤهش، ابتدا ساختار الكترونى داروى

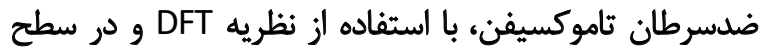

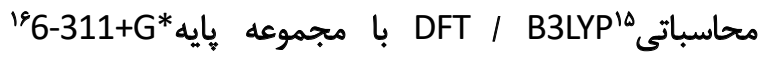

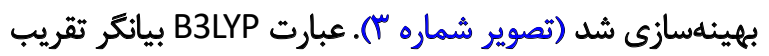

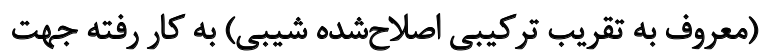

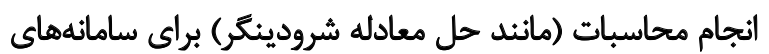

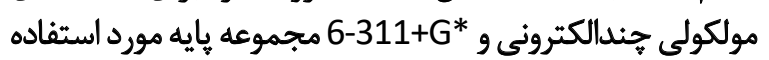

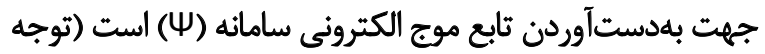

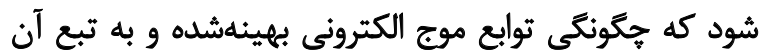

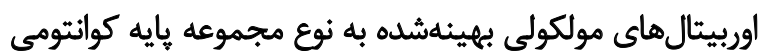

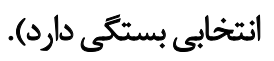

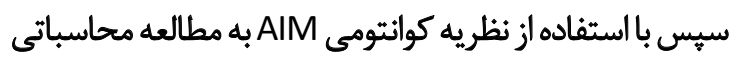

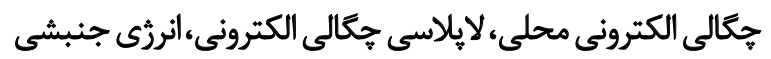

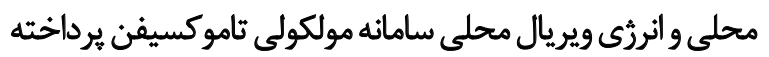

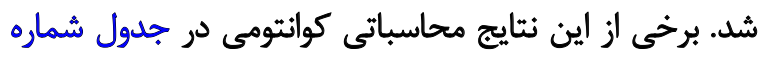

15. Becke, 3-parameter, Lee-Yang-Parr functional/approximation 16. Basis Set 


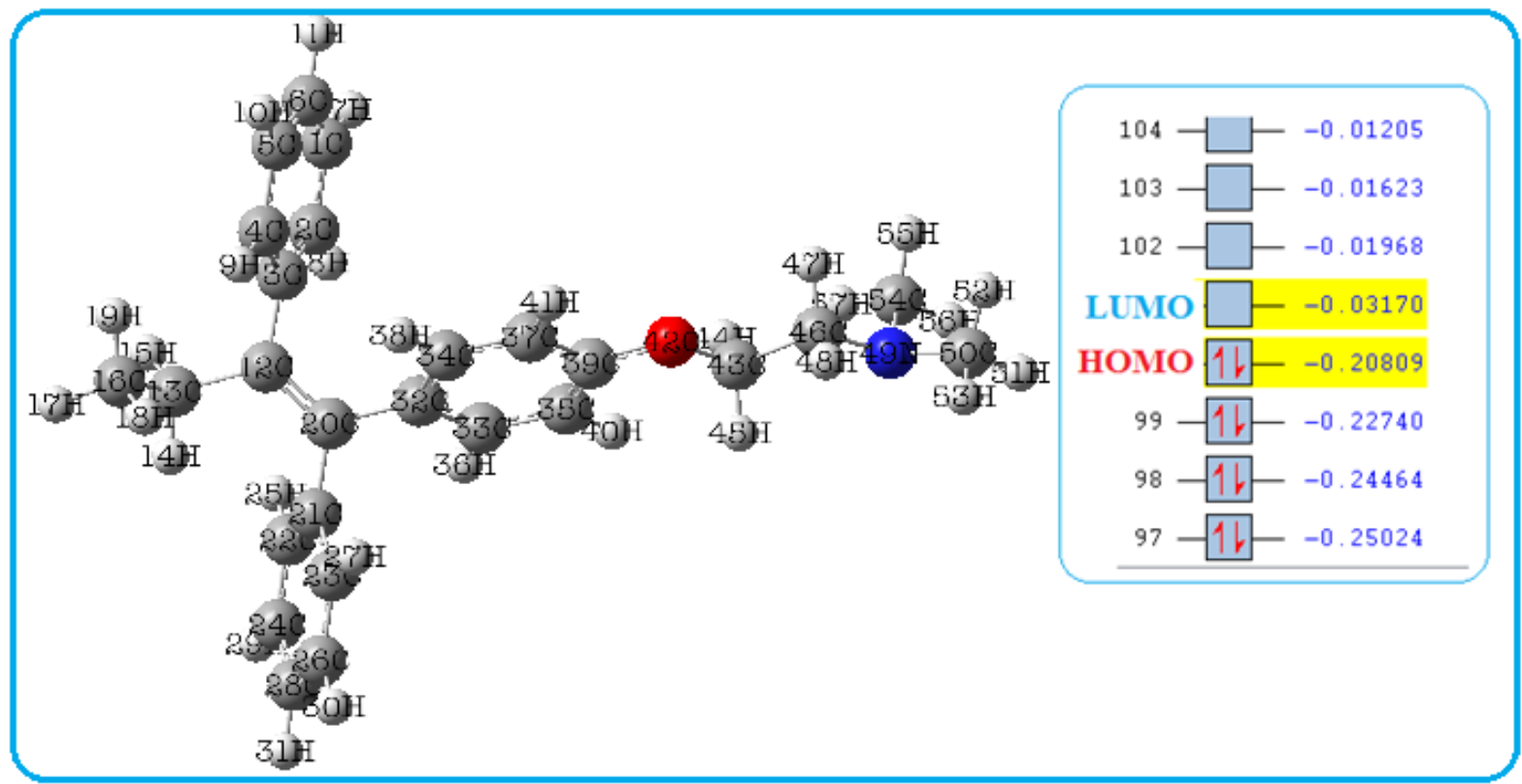

\section{通}

تصوير "r. ساختار الكترونى بهينه شده (يايدار) داروى ثاموكسيفن با استفاده از نرمافزار كوسين (G09) و بر اساس روش محاسباتى

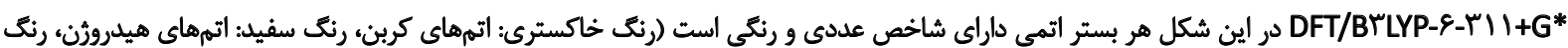

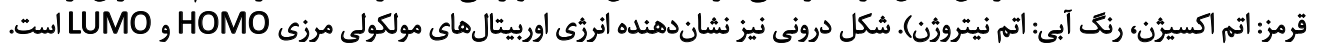

$\mathrm{K}_{\text {elec }}(\Omega)$
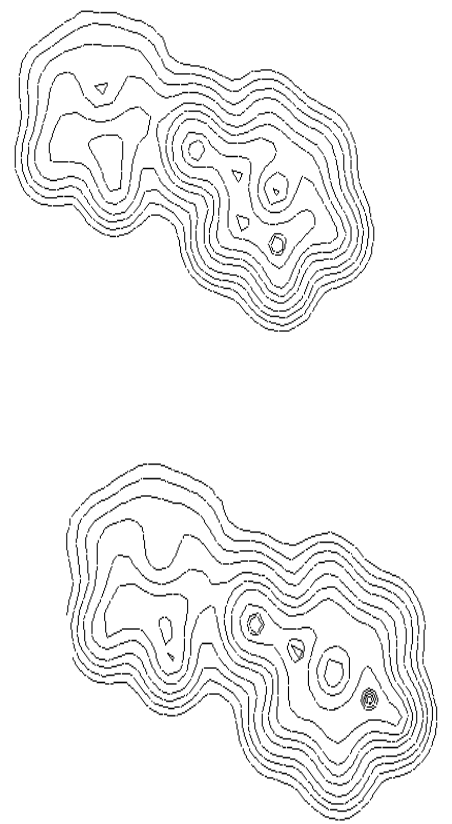

$\nabla^{2} p(\Omega)$ Field $=0$ a.u.

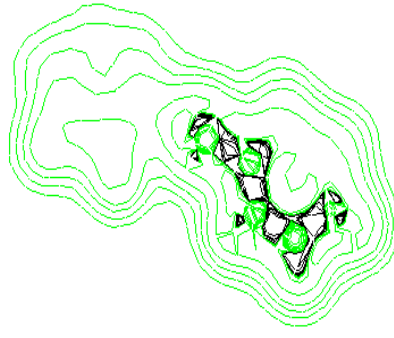

Field $=50 \times 10-4 a . u$

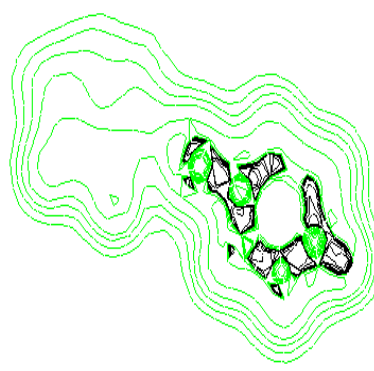

$\mathrm{p}(\Omega)$
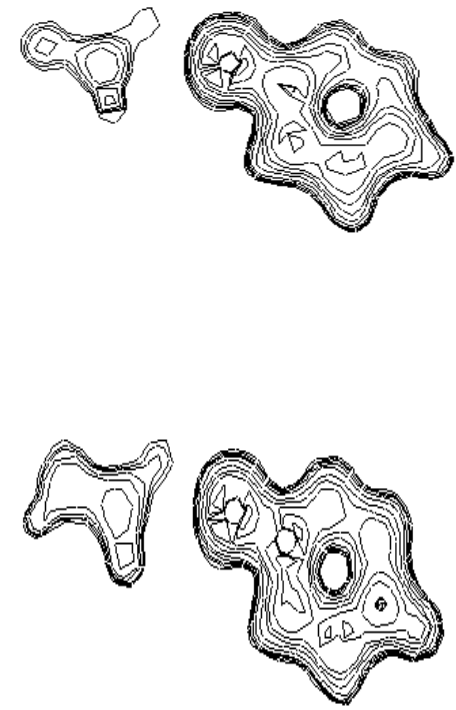

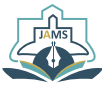

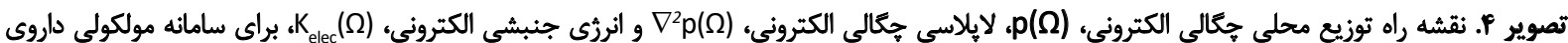

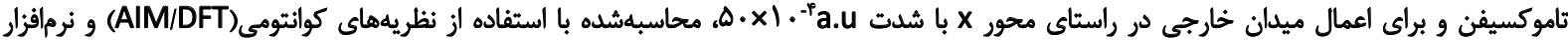



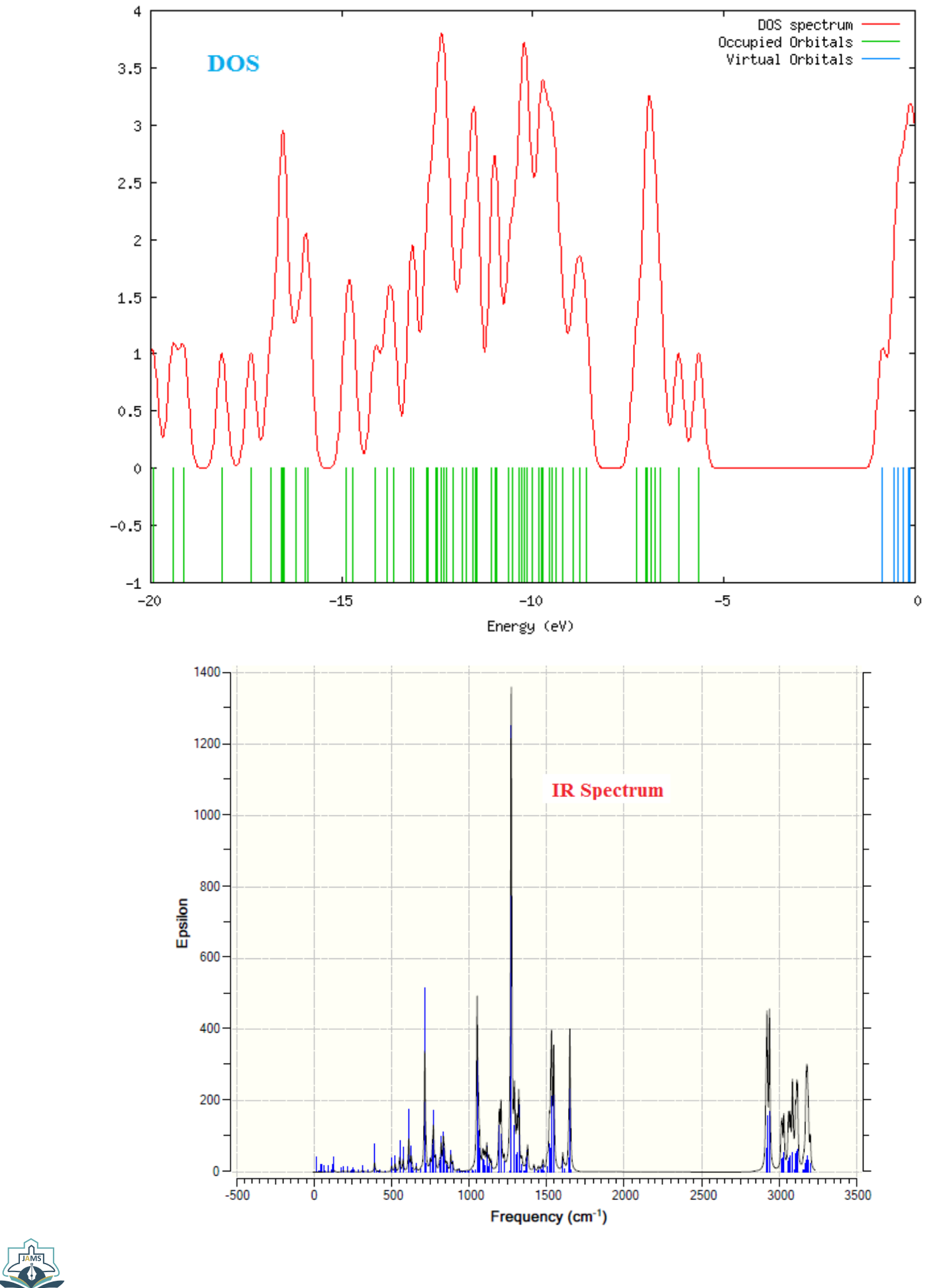

تصوير ه. طيف ارتعاشى IR (الف) و نمودار جكالى حالات DOS (ب)، هر دو محاسبهشه براى سامانه مولكولى ثاموكسيفن با استفاده از نرمافزار توسين (G09)

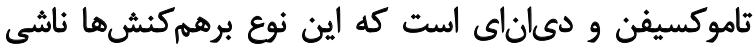

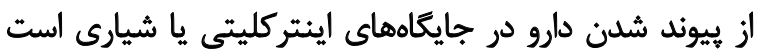

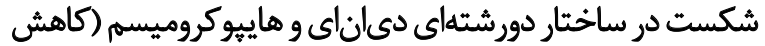

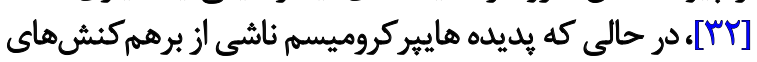

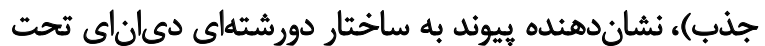

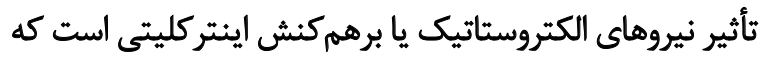

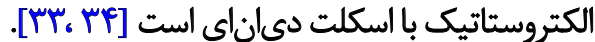

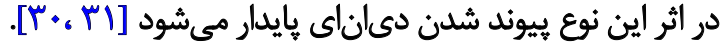
يديده هاييوكروميسم ناشى از برهمكنشهاى هيدروفوب بين تحليل نتايج طيفسنجى اين بروهش نشان مىدهد كه 


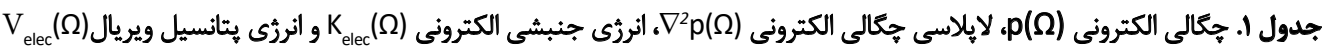

\begin{tabular}{|c|c|c|c|c|}
\hline بستر اتمى & $p(\Omega)$ & $\nabla^{2} p(\Omega)$ & $K_{\text {elec }}(\Omega)$ & $V_{\text {elec }}(\Omega)$ \\
\hline $\mathrm{C} 12$ & el. H & - I. papa. & m/que & $-v \varepsilon / \pi+q$ \\
\hline $\mathrm{C} 20$ & 91.18 & $.1 .8 M$ & rV/qIT & -VE/rat \\
\hline 042 & Q/MT & -.1 .0180 & $V \Delta / 81{ }^{\prime}$ & $-|\Delta T /| M T$ \\
\hline N49 & vaes & $-.1 .0 \Delta Y \Delta$ & $\Delta f / u$. & $-11.18 \mathrm{rr}$ \\
\hline C54 & $\Delta / N T \Lambda$ & $\cdot 1 \cdot \cdot V \Delta P$ & rV/VOV & $-V \Delta / V a s$ \\
\hline
\end{tabular}

براى برخى از بسترهاى اتمى شاخص (نشان دادشده در تصوير شماره \&) داروى تاموكسيفن، محاسبهشده با استفاده از نظريه كوانتومى اتم در مولكول (AIM).

HOMO تحت نام شكاف (HLGEЕ

در بسيارى از سامانههاي مولكولى ميزان شكاف HLG معيار

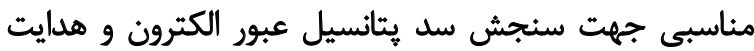

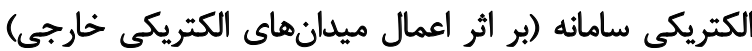

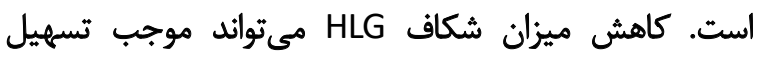

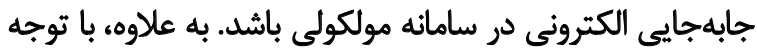

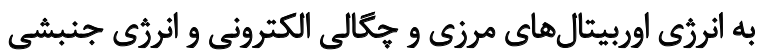

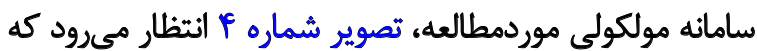

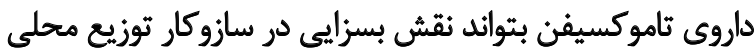

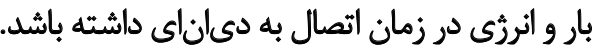

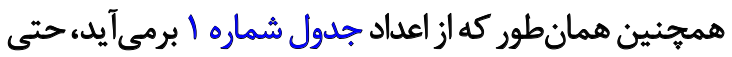

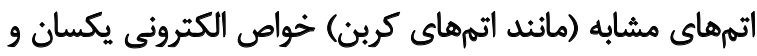

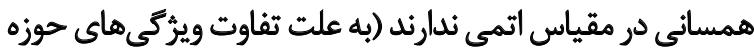

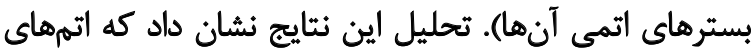

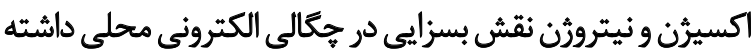

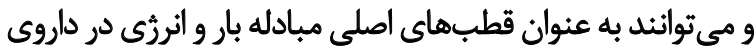

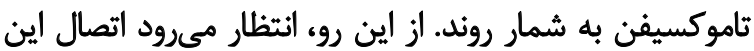

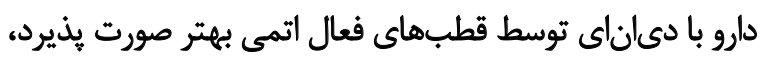

$$
\text { (تصوير شماره ع). }
$$

وجود ساختارهاى آروماتيك حلقوى در ثاموكسيفن مى بتواند

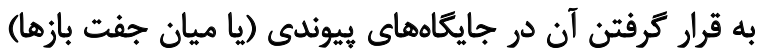

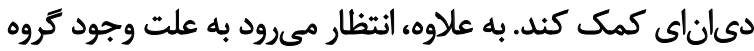

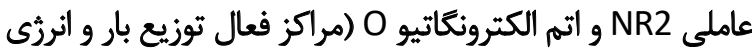

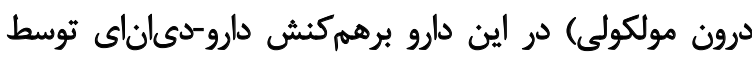
ايجاد بيوندهاى درون مولكولى (با اتصالات عرضى دئ دئ دانياي)

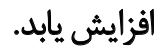
به علاوه، بررسى ساختار ارتعاشى (IR) و خواص ترموديناميكى
برهمكنشهاى هيدروفوب و الكتروستاتيك بين دىانياى

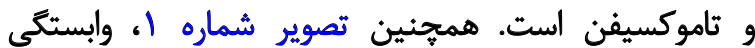

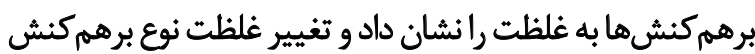

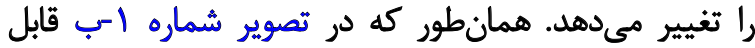

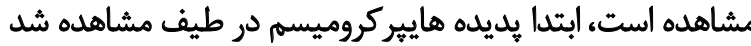

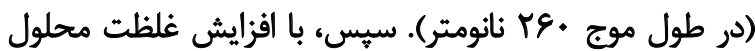

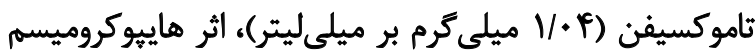

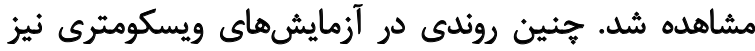

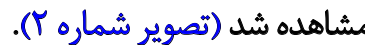

به طور اجمال، افزايش و كاهش در ويسكوزيته محلول مى نوتواند

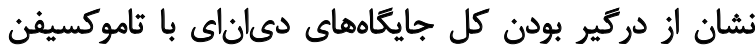

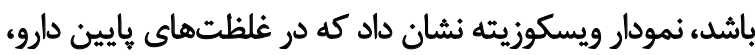

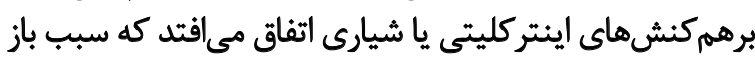

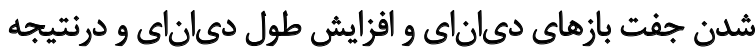

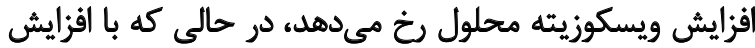

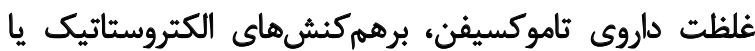

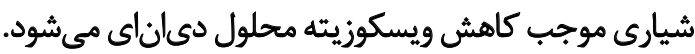
با توجه به نتايج حاصلشده از بخش تجربى وييوند دارو با

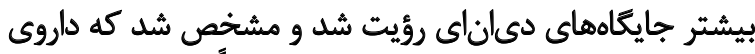

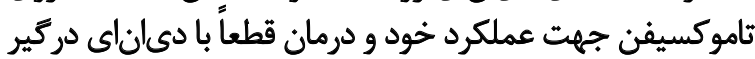

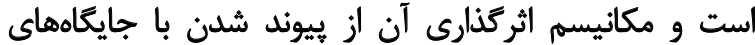

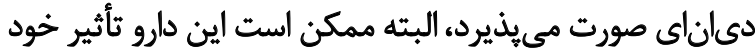

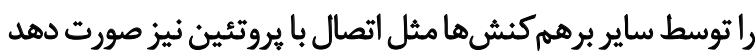

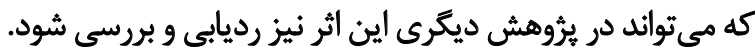

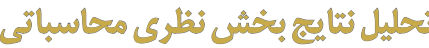

تحليل نتايج بخش محاسباتى كوانتومى (AIM و DFT) اين

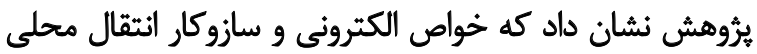

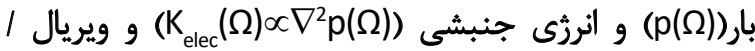

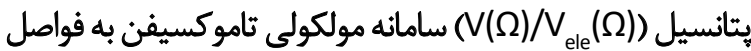

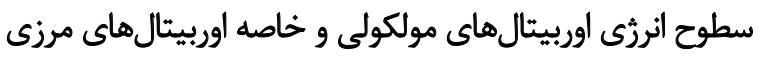




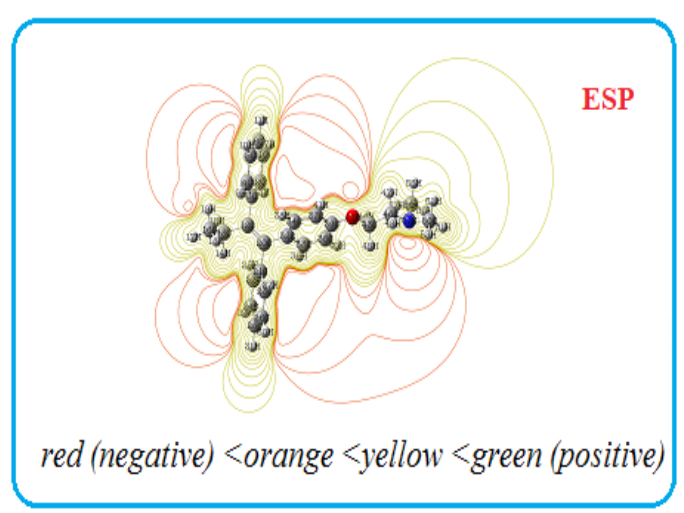

(ب)

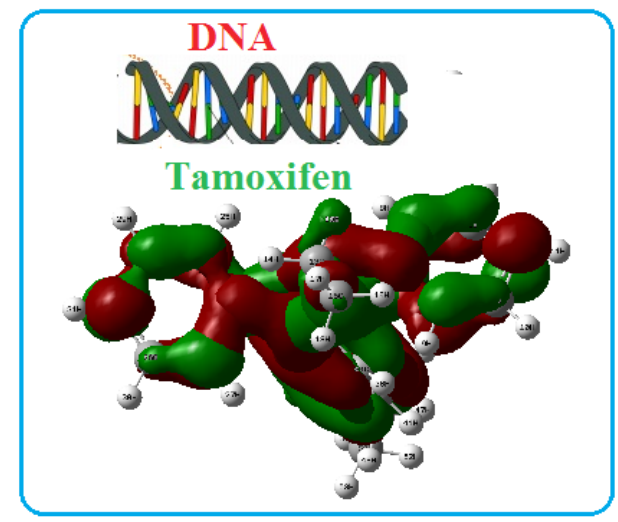

(s)

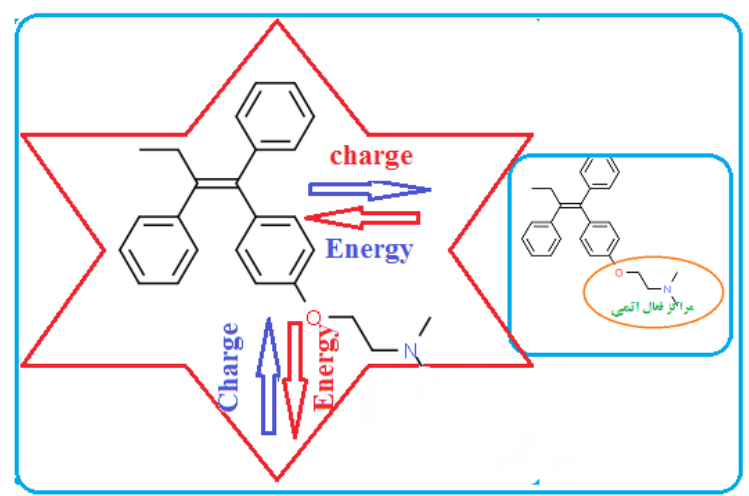

(الف)

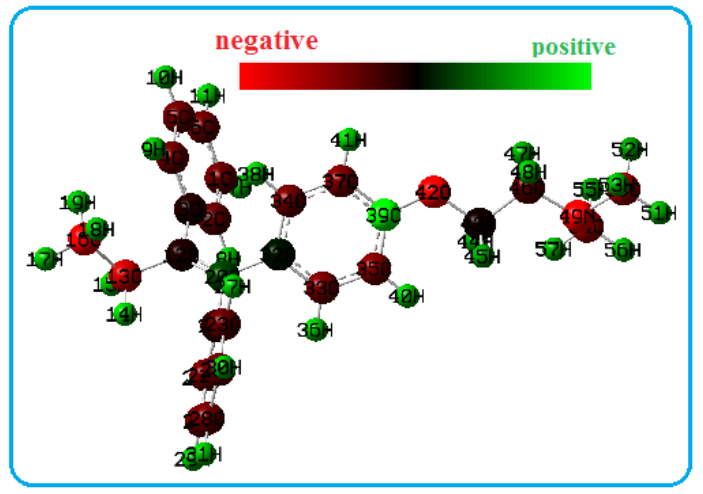

(द)

\section{(5it)}

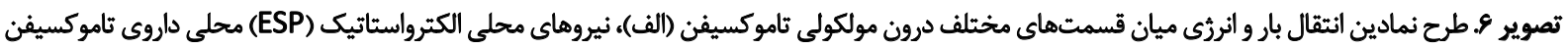

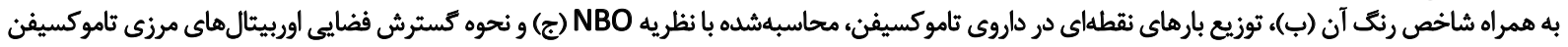

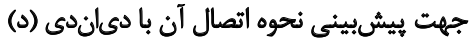
مجاسبات با استفاده از نرمافزار توسين (G و (G) انجام شده است.

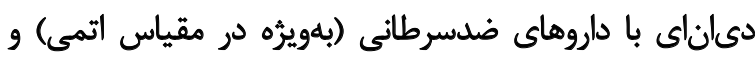

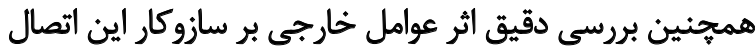

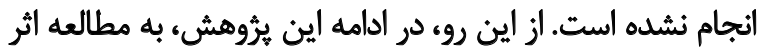

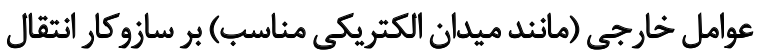

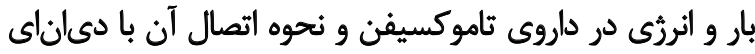
يرداخته خواهد شد.

هرجند يُروهش هاى تكميلى بيرامون اين موضوع در حال انجام

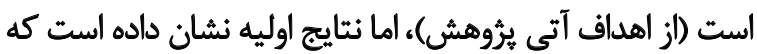

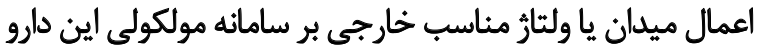

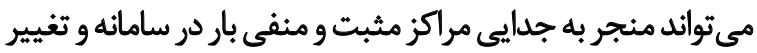

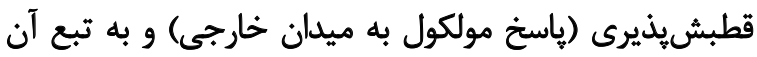

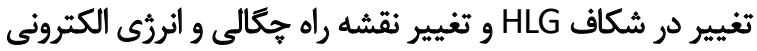

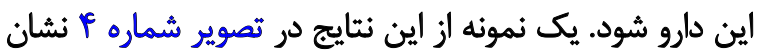

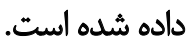

بر اساس تحليل نتايج اثرميدان مىثوان بيشبينى كرد كه
اين دارو نشان داد كه از بايدارى خوبيى در شرايط استاندارد

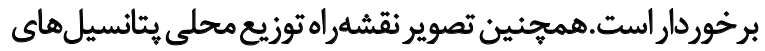

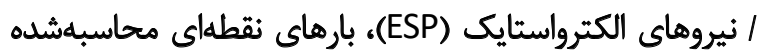

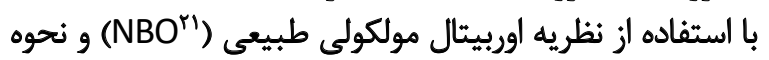
كسترش اوربيتال هاى مرزى داروى تاموكسيفن در تصوير شماره ع نشان داده شده است.

همانطور كه از اين تصوير برمىآيد، توزيع بارها و نيروهاى

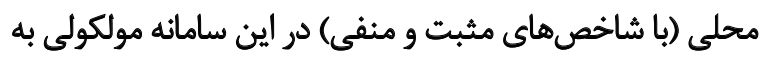

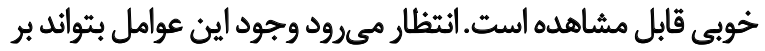

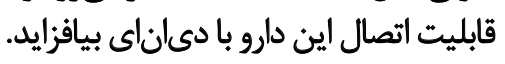

اترجه تاكنون يُوهشهاى بيرامون اثر درمانى تاموكسيفن

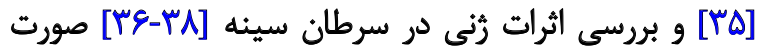

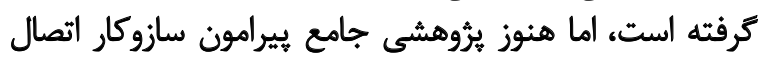


وجود برهم كنش هاى الكترواستاتيكى درون مولكولى نسبتًا قابل

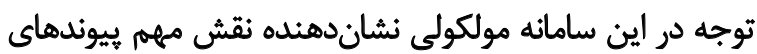

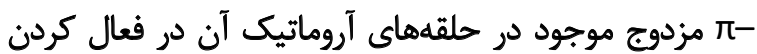
نقاط جذب سطحى در صفحه مولكولى اين دارو است.

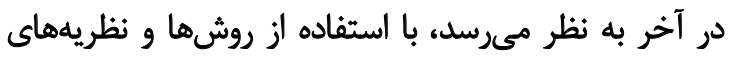

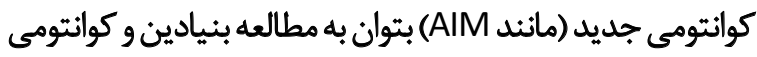

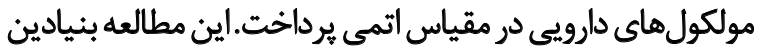

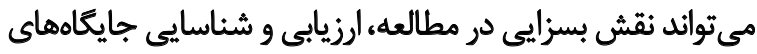

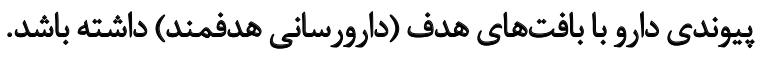

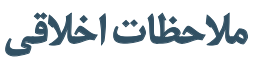

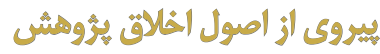

با توجه به اينكه مطالعه روى دى اناى غيرانسانى است، نياز به

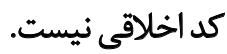

Jlo on

اين مقاله از ياياننامه كارشناسى ارشد نويسنده اول در كروه

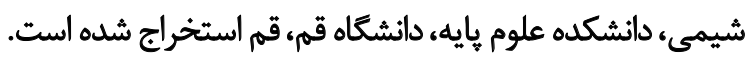

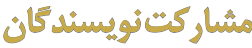

طرح موضوع: رضا صفرى، مريم نجات دهكردى، انجام

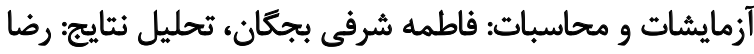

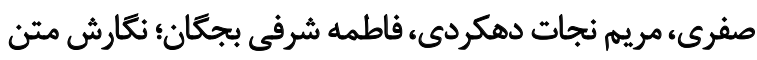

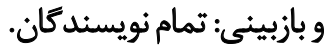

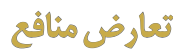

نويسند حان اعلام مى دارند كه هيجگونه ثضاد منافعى در

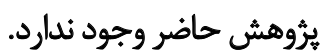

\section{تشكر و قدوهاني}

از معاونين بثروهشى و مدير تروههاى محترم رشته شيمى

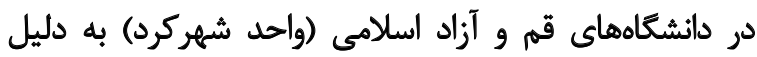

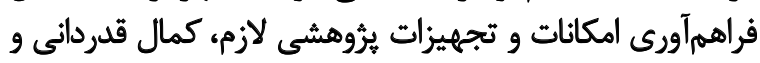

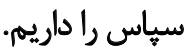

سامانه مولكولى اين دارو را بتوان به بخشهاي درون مولكولى بحتي

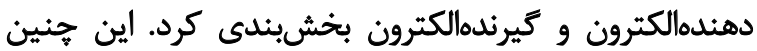

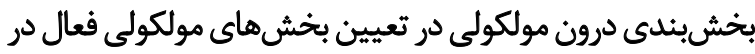

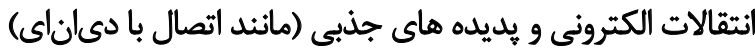

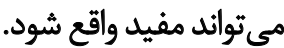

\section{نتيجهيَيرى}

تركيباتى كه در ساختار خود بخش آروماتيك بيشترى داشته

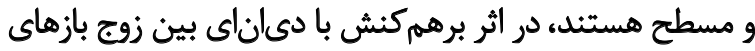

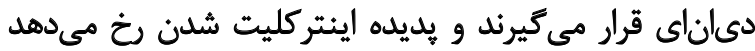

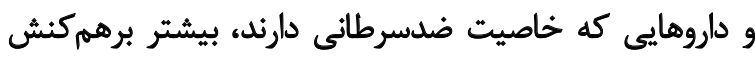

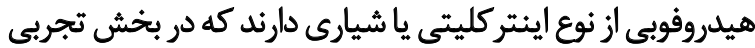

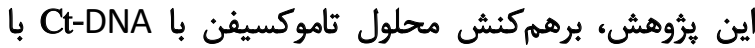

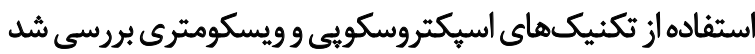

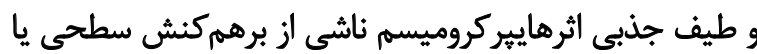

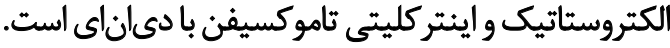

اما اثر هاييوكروميسم نشان از برهمكنشهاي هيدروفوب

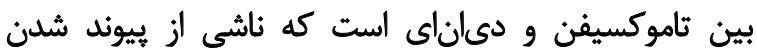

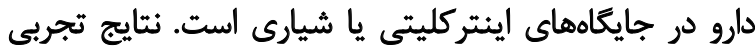

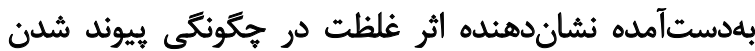

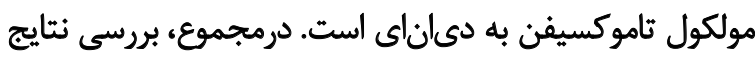

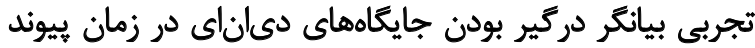

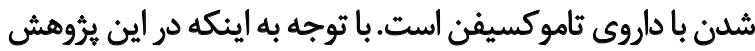

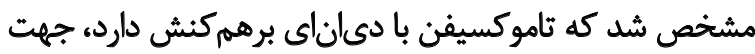

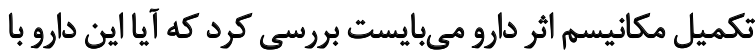

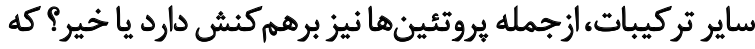

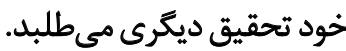

به علاوه، ارزيابى ساختار كوانتومى مولكول تاموكسيفن و وانئ

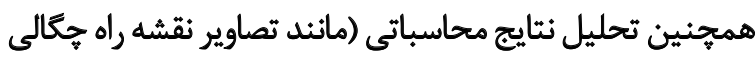

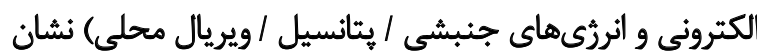

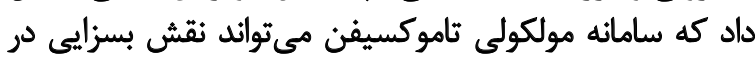

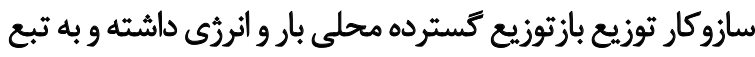

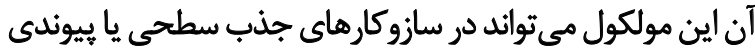

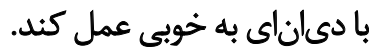

تحليل نتايج DFT / AIM نشان داد كه اتمهاى اكسيرن و

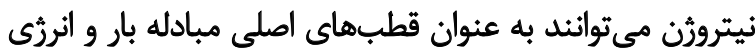

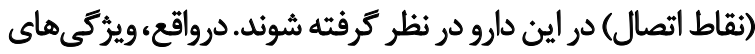

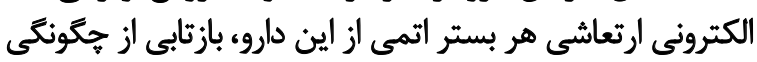

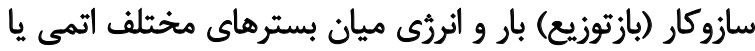
بخشهاى مختلف درون مولكولى در اين دارئ بارو است.

همجنين هايدارى ترموديناميكى و فاصله مناسب ميان

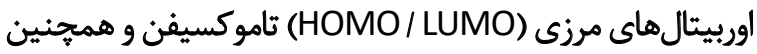




\section{References}

[1] Shokohi-Pour Z, Chiniforoshan H, Sabzalian MR, Esmaeili SA, MomtaziBorojeni AA. Cobalt (II) complex with novel unsymmetrical tetradentate Schiff base (ON) ligand: In vitro cytotoxicity studies of complex, interaction with DNA/protein, molecular docking studies, and antibacterial activity. J Biomol Struct Dyn. 2018; 36(2):532-49. [DOI:10.1080/07391102.2017.12 87006] [PMID]

[2] Agudelo D, Bourassa P, Bérubé G, Tajmir-Riahi HA. Review on the binding of anticancer drug doxorubicin with DNA and tRNA: Structural models and antitumor activity. J Photochem Photobiol B. 2016; 158:274-9. [DOI:10.1016/j.jphotobiol.2016.02.032] [PMID]

[3] Liu W, Guo Y, Wang K, Zhou X, Wang Y, Lü J, et al. Atomic force microscopybased single-molecule force spectroscopy detects DNA base mismatches. Nanoscale. 2019; 11(37):17206-10. [DOI:10.1039/C9NR05234H] [PMID]

[4] Patel HK, Bihani T. Selective estrogen receptor modulators (SERMs) and selective estrogen receptor degraders (SERDs) in cancer treatment. Pharmacol Ther. 2018; 186:1-24. [DOI:10.1016/j.pharmthera.2017.12.012] [PMID]

[5] Gong L, Tang H, Luo Z, Sun X, Tan X, Xie L, et al. Tamoxifen induces fatty liver disease in breast cancer through the MAPK8/FoxO pathway. Clin Transl Med. 2020; 10(1):137-50. [DOI:10.1002/ctm2.5] [PMID] [PMCID]

[6] Shagufta, Ahmad I. Tamoxifen a pioneering drug: An update on the therapeutic potential of tamoxifen derivatives. Eur J Med Chem. 2018; 143:51531. [DOI:10.1016/j.ejmech.2017.11.056] [PMID]

[7] Di Benedetto L, Giovanale V, Caserta D. Endometrial tubal metaplasia in a young puerperal woman after breast cancer. Int J Clin Exp Pathol. 2015; 8(6):7610-3. [PMCID]

[8] Burstein HJ, Temin S, Anderson H, Buchholz TA, Davidson NE, Gelmon $\mathrm{KE}$, et al. Adjuvant endocrine therapy for women with hormone receptor-positive breast cancer: American society of clinical oncology clinical practice guideline focused update. J Clin Oncol. 2014; 32(21):2255-69. [DOI:10.1200/JCO.2013.54.2258] [PMID] [PMCID]

[9] Hassan AA, Aly AA, Mohamed NK, El Shaieb KM, Makhlouf MM, Abdelhafez EMN, et al. Design, synthesis, and DNA interaction studies of furoimidazo [3.3.3] propellane derivatives: Potential anticancer agents. Bioorg Chem. 2019; 85:585-99. [DOI:10.1016/j.bioorg.2019.02.027] [PMID] [PMCID]

[10] Dareini M, Amiri Tehranizadeh Z, Marjani N, Taheri R, Aslani-Firoozabadi $S$, Talebi $A$, et al. A novel view of the separate and simultaneous binding effects of docetaxel and anastrozole with calf thymus DNA: Experimental and in silico approaches. Spectrochim Acta A Mol Biomol Spectrosc. 2020; 228:117528. [DOI:10.1016/j.saa.2019.117528] [PMID]

[11] Nejat Dehkordi M, Akerman B. Interaction of DNA with water soluble complex of Nickle and formation of DNA cross-links. Chem Biol Interact. 2018; 282:55-62. [DOI:10.1016/j.cbi.2018.01.007] [PMID]

[12] Tan LF, Liu XH, Chao H, Ji LN. Synthesis, DNA-binding and photocleavage studies of ruthenium (II) complex with 2-(3'-phenoxyphenyl) imidazo [4, 5-f] [1, 10] phenanthroline. J Inorg Biochem. 2007; 101(1):56-63. [DOI:10.1016/j.jinorgbio.2006.08.006] [PMID]

[13] Brodzki A, Tatara MR, Brodzki P, Balicki I. DNA adduct assessment during antihormonal treatment of perianal gland tumors with tamoxifen in male dogs. In Vivo. 2019; 33(3):731-5. [DOI:10.21873/invivo.11532] [PMID] [PMCID]

[14] Rajaniemi H, Koskinen M, Mäntylä E, Hemminki K. DNA binding of tamoxifen and its analogues: Identification of the tamoxifen-DNA adducts in rat liver. Toxicol Lett. 1998; 102-3:453-7. [DOI:10.1016/S03784274(98)00338-5]
[15] Matta CF, Boyd RJ. The quantum theory of atoms in molecules: From solid state to DNA and drug design. Germany: Wiley; 2007. [DOI:10.1002/9783527610709]

[16] 16. Shameera Ahamed TK, Rajan VK, Sabira K, Muraleedharan K DFT and QTAIM based investigation on the structure and antioxidant behavior of lichen substances Atranorin, Evernic acid and Diffractaic acid. Comput Biol Chem. 2019; 80:66-78. [DOI:10.1016/j.compbiolchem.2019.03.009] [PMID]

[17] Dehkordi MN, Bordbar AK, Mehrgardi MA, Mirkhani V. Spectrophotometric study on the binding of two water soluble Schiff base complexes of $\mathrm{Mn}$ (III) with ct-DNA. J Fluoresc. 2011; 21(4):1649-58. [DOI:10.1007/ s10895-011-0854-y] [PMID]

[18] Zhao Z, Li E, Qin Y, Liu X, Zou Y, Wu H, et al. Density functional theory (DFT) studies of vanadium-titanium based selective catalytic reduction (SCR) catalysts. J Environ Sci (China). 2020; 90:119-37. [DOI:10.1016/j. jes.2019.11.008] [PMID]

[19] Rojas S, Parravicini O, Vettorazzi M, Tosso R, Garro A, Gutiérrez L, et al. Combined MD/QTAIM techniques to evaluate ligand-receptor interactions. Scope and limitations. Eur J Med Chem. 2020; 208:112792. [DOI:10.1016/j.ejmech.2020.112792] [PMID]

[20] Matta CF. Modeling biophysical and biological properties from the characteristics of the molecular electron density, electron localization and delocalization matrices, and the electrostatic potential. J Comput Chem. 2014; 35(16):1165-98. [DOI:10.1002/jcc.23608]

[21] Hammoudan I, Chtita S, Riffi-Temsamani D. QTAIM and IRC studies for the evaluation of activation energy on the $\mathrm{C}=\mathrm{P}, \mathrm{C}=\mathrm{N}$ and $\mathrm{C}=\mathrm{O}$ Diels-Alder reaction. Heliyon. 2020; 6(8):e04655. [DOI:10.1016/j.heliyon.2020. e04655] [PMID] [PMCID]

[22] Levine IN. Quantum chemistry. London: Person; 2013.

[23] Biegler F, Schonbohm H, Bader RWF. AIM2000 Program Package, Ver. 2.0. Canada, Hamilton: McMaster University; 2002.

[24] 24. von Rudorff GF, von Lilienfeld OA. Atoms in molecules from alchemical perturbation density functional theory. J Phys Chem B. 2019; 123(47):10073-82. [DOI:10.1021/acs.jpcb.9b07799] [PMID]

[25] Shahbazy M, Pakravan P, Kompany-Zareh M. Multivariate spectrochemical analysis of interactions of three common Isatin derivatives to calf thymus DNA in vitro. J Biomol Struct Dyn. 2017; 35(12):2539-56. [D OI:10.1080/07391102.2016.1225604] [PMID]

[26] Soni A, Khurana P, Singh T, Jayaram B. A DNA intercalation methodology for an efficient prediction of ligand binding pose and energetics. Bioinformatics. 2017; 33(10):1488-96. [DOI:10.1093/bioinformatics/ btx006] [PMID]

[27] Cui F, Liu Q, Luo H, Zhang G. Spectroscopic, viscositic and molecular modeling studies on the interaction of 3 '-azido-daunorubicin thiosemicarbazone with DNA. J Fluoresc. 2014; 24(1):189-95. [DOI:10.1007/ s10895-013-1285-8] [PMID] [PMCID]

[28] Shahabadi N, Mohammadi S, Alizadeh R. DNA interaction studies of a new platinum(II) complex containing different aromatic dinitrogen ligands. Bioinorg Chem Appl. 2011; 2011:429241. [DOI:10.1155/2011/429241] [PMID] [PMCID]

[29] Krokidis MG, Molphy Z, Efthimiadou EK, Kokoli M, Argyri SM, Dousi I, et al. Assessment of DNA topoisomerase I unwinding activity, radical scavenging capacity, and inhibition of breast cancer cell viability of $\mathrm{N}$-alkyl-acridones and N,N'-dialkyl-9,9'-biacridylidenes. Biomolecules. 2019; 9(5):177. [DOI:10.3390/biom9050177] [PMID] [PMCID] 
[30] Qais FA, Ahmad I. In vitro interaction of cefotaxime with calf thymus DNA: Insights from spectroscopic, calorimetric and molecular modelling studies. J Pharm Biomed Anal. 2018; 149:193-205. [DOI:10.1016/j. jpba.2017.10.016] [PMID]

[31] Rahman Y, Afrin S, Husain MA, Sarwar T, Ali A, Shamsuzzaman, et al. Unravelling the interaction of pirenzepine, a gastrointestinal disorder drug, with calf thymus DNA: An in vitro and molecular modelling study. Arch Biochem Biophys. 2017; 625-6:1-12. [DOI:10.1016/j. abb.2017.05.014] [PMID]

[32] Nogueira JJ, Plasser F, González L. Electronic delocalization, charge transfer and hypochromism in the UV absorption spectrum of polyadenine unravelled by multiscale computations and quantitative wavefunction analysis. Chem Sci. 2017; 8(8):5682-91. [DOI:10.1039/C7SC01600J] [PMID] [PMCID]

[33] Das RP, Singh BG, Kunwar A, Ramani MV, Subbaraju GV, Hassan PA, et al. Tuning the binding, release and cytotoxicity of hydrophobic drug by Bovine Serum Albumin nanoparticles: Influence of particle size. Colloids Surf B Biointerfaces. 2017; 158:682-8. [DOI:10.1016/j.colsurfb.2017.07.048] [PMID]

[34] Shahabadi N, Hakimi M, Morovati T, Fatahi N. DNA binding affinity of a macrocyclic copper (II) complex: Spectroscopic and molecular docking studies. Nucleosides Nucleotides Nucleic Acids. 2017; 36(8):497-510. [D OI:10.1080/15257770.2017.1332370] [PMID]

[35] Shahabadi N, Akhtarshenas S, Hadidi S. Synthesis, characterization and DNA interaction studies of new copper complex containing pseudoephedrine hydrochloride drug. Nucleosides Nucleotides Nucleic Acids. 2019; 38(9):680-99. [DOI:10.1080/15257770.2019.1599909] [PMID]

[36] Karimi Moghadam S, Dorostkar R, Hesami Takallou S. [Evaluation of human endogenous retrovirus $\mathrm{K}$ expression in the blood of breast cancer patients (Persian)]. J Arak Univ Med Sci. 2018; 20(11):87-95. https:// www.sid.ir/FileServer/JF/651139612809

[37] Yousefi Z, F Homayie, S Rafei. [The evaluation of the endometrial thickness of amenorrhea breast cancer patients treated with tamoxifen (Persian)]. J Arak Univ Med Sci. 2011; 14(5):101-7. https://www.sid.ir/en/ journal/ViewPaper.aspx?id=215602

[38] Anoushirvani AA, Ahmadi A, Aghabozorgi R, Khalili S, Sahraei M, Fereydouni T, et al. [Gengenotypic evaluation of Hsa-miR-433-3p binding site in the regulatory region of TYMS in breast cancer patients (Persian)]. J Arak Univ Med Sci. 2018; 21(2):1-9. http://jams.arakmu.ac.ir/article1-5608-en.pdf 
This Page Intentionally Left Blank 